Marquette University

e-Publications@Marquette

College of Nursing Faculty Research and

Publications

Nursing, College of

$1-2016$

\title{
Translating Research to Practice for Children With Autism \\ Spectrum Disorder: Part 2: Behavior Management in Home and Health Care Settings
}

\author{
Margaret W. Bultas \\ Saint Louis University \\ Norah L. Johnson \\ Marquette University, norah.johnson@marquette.edu \\ Karen Burkett \\ Cincinnati Children's Hospital Medical Center \\ Judy Reinhold \\ Cincinnati Children's Hospital Medical Center
}

Follow this and additional works at: https://epublications.marquette.edu/nursing_fac

Part of the Nursing Commons

\section{Recommended Citation}

Bultas, Margaret W.; Johnson, Norah L.; Burkett, Karen; and Reinhold, Judy, "Translating Research to Practice for Children With Autism Spectrum Disorder: Part 2: Behavior Management in Home and Health Care Settings" (2016). College of Nursing Faculty Research and Publications. 424.

https://epublications.marquette.edu/nursing_fac/424 


\section{Marquette University}

\section{e-Publications@Marquette}

\section{College of Nursing Faculty Research and Publications/ College of Nursing}

This paper is NOT THE PUBLI SHED VERSI ON; but the author's final, peerreviewed manuscript. The published version may be accessed by following the link in th citation below.

J ournal of Pediatric Health Care, Vol. 30, No. 1 (January/February 2018): 27-37. DOI. This article is (c) Elsevier and permission has been granted for this version to appear in e-Publications@Marquette. Elsevier does not grant permission for this article to be further copied/distributed or hosted elsewhere without the express permission from Elsevier.

\section{Translating Research to Practice for Children with Autism Spectrum Disorder: Part 2: Behavior Management in Home and Health Care Settings}

\section{Margaret W. Bultas}

School of Nursing, Saint Louis University, St. Louis, MO

Norah L. Johnson

College of Nursing, Marquette University, Milwaukee, WI

Karen Burkett

Cincinnati Children's Hospital Medical Center, Cincinnati, $\mathrm{OH}$

Judy Reinhold

Cincinnati Children's Hospital Medical Center, Cincinnati, $\mathrm{OH}$

\section{Abstract}

Introduction

Managing home and health care for children with autism spectrum disordercan be challenging because of the range of symptoms and behaviors exhibited. 


\section{Method}

This article presents an overview of the emerging science related to the methods to foster family selfmanagement of common concerns regarding activities of daily living and behaviors, as well as for the health care provider in primary and acute health care settings.

\section{Results}

Recommendations are provided to enhance the overall delivery of services, including understanding and managing a child's challenging behaviors, and supporting family management of common activities of daily living and behaviors.

\section{Discussion}

Health care providers' knowledge of evidence-based recommendations for providing care, supporting family self-management of common concerns, and referral heighten the likelihood of better outcomes for children with autism spectrum disorder.

\section{Key Words}

Autism spectrum disorder, autism, management, home, health care

Behavior issues are a significant problem for children with autism spectrum disorder (ASD). Social and communication impairments, anxiety, and fear can lead to challenging behaviors in the health care setting and can be further complicated by mental health comorbidities (Mayes et al., 2012). Children with ASD have more contact with the health care environment than typically developing children, including children with chronic health conditions ( $\mathrm{Wu}, \mathrm{Kung}, \mathrm{Li}, \& \mathrm{Tsai}, 2015)$. Health care expenditures have been found to be up to nine times greater for a child with ASD because of increased comorbidities, increased use of medications, challenging child behaviors, and the behavioral complexity of providing care to this population (Gurney, McPheeters, \& Davis, 2006; Liptak, Stuart, \& Auinger, 2006; Mandell, Cao, Ittenbach, \& Pinto-Martin, 2006; Tregnago \& Cheak-Zamora, 2012; Wu et al., 2015). Parents and health care providers (HCPs), including nurses and nurse practitioners (NPs), have both expressed concerns related to ineffective management of challenging behaviors in the health care setting for children with ASD (Minnes \& Steiner, 2009; Rhoades, Scarpa, \& Salley, 2007; Weil \& Inglehart, 2010).

This review article provides an overview of the current evidence available to support HCPs. In addition, anticipatory guidance for behavior management for families of children with ASD in the home, as well as in primary and acute health care settings, is presented.

\section{Management in the Home}

Family self-management includes efforts that family members make to incorporate chronic condition management into everyday life (Grey, Schulman-Green, Knafl, \& Reynolds, 2015). Family self-management is paramount to ensuring the best possible outcomes. Frequently, HCPs are asked to provide answers to general parenting questions ranging from common discipline techniques to self-help skills for children with ASD. Providing discipline and teaching self-help skills can be challenging for all parents but is more complex for the child with ASD because of developmental delays, insistence of routine, and difficulty with communication. Although children with ASD may be receiving school-based services and therapies, few outside supports exist specifically for parents who need help with challenging behaviors and concerns at home (McMillin, Bultas, Wilmott, Grafeman, \& Zand, 2015). The Autism Speaks Web site (www.autismspeaks.org) provides many useful 
resources for parents at no cost. Parenting programs have been developed so families can better manage challenging behaviors. Several of these programs are described in this article.

\section{Shaping Desired Behavior in General}

Many evidence-based positive parenting programs based on social learning theory are available and can help provide parenting supports for parents of all children, including children with ASD. Positive parenting approaches, in general, focus on engaging the child and conveying positive regard. Three parenting programs that have been used with parents of children with ASD include the Incredible Years (Webster-Stratton \& Mihalic, 2001), Triple P Positive Parenting Program (Sanders, Mazzucchelli, \& Studman, 2009a), and Nurturing Parenting (Bavolek, 1989).

First, teaching parents to understand the " $A B C$ ' $s$ " of behavior is a helpful technique in understanding and reducing challenging behaviors in the home (Autism Speaks, 2012b). The antecedent $(A)$ is the event or situation that happened just prior to the behavior (B) and triggers the behavior. The consequence $(C)$ is what happened just after the behavior and may reinforce the behavior. When parents take the time to analyze the behavior in relation to the "ABCs," they learn to identify antecedent triggers and consequences to the behavior such as escaping a task or obtaining attention that maintains or reinforces the behavior. If the child is rewarded by the poor behavior, they were successful in getting what they wanted rather than what is appropriate; therefore, the behavior may continue or even escalate.

Several key strategies also can be taught to parents to help shape desired behavior. One is to positively praise desired behavior while using planned ignoring of undesirable behavior (Sanders et al., 2009a). Most children enjoy receiving attention and praise. If children do not receive attention for desired behavior, they may learn to engage in undesired behavior as a way to gain attention from the parent. Establishment of simple rules is another helpful strategy (Sanders et al., 2009a). Parents should establish several key rules for the household and consistently reinforce these rules (Autism Speaks, 2012b). The rules can be posted in a central location as a reminder for the child. In addition, encouraging parents to provide a variety of stimulating and developmentally appropriate activities for their child reduces the boredom behaviors that often turn into inappropriate behaviors (Sanders et al., 2009a). The Consumer Product Safety Commission provides a resource that can be provided to parents and identifies toys appropriate for children of different ages (Goodson \& Bronson, n.d.). Suggesting that parents provide children with transitional prompts when moving from one activity to another or before a change in routine also reduces tantrums or undesired behaviors for children (Autism Speaks, 2012b). A suggestion would be to provide a 5-minute prompt or "count down" from 10 as the child transitions to the next activity.

Parents should have a method, available in the home, for the child to communicate. Communication resources may include picture cards, a communication board, or an augmentative communication device that provides an avenue for the child to express desires, needs, and reduce frustrations (Loring \& Hamilton, 2011). Visual and activity schedules can be incorporated into the home to either establish desired routines or to prepare the child for a change in routine.

\section{Managing Challenging Behavior in the Home}

As a guideline, for children developmentally younger than 3 years, the consequence for poor behavior should be focused on redirection or diverting the behavior rather than punishment (Autism Speaks, 2012b). For children with a developmental level greater than 3 years, removal from the situation or removal of the desired action or 
toy may be more appropriate. Although "time out" can be a useful discipline technique, it should be used as a last resort after the child has been given opportunities to succeed (Sanders et al., 2009a). When placed in "time out," children should be in a dull place, but one that is not scary, and in view of the parent. A general guideline is to use 1 minute per year of age for "time out" time. When "time out" is used, parents should ensure that "time in" is pleasurable and enjoyable for the child (Autism Speaks, 2012b). Above all, parents should be advised to remain calm in all situations and provide clear instructions for the child.

Interventions and recommendations are available for families that provide them with anticipatory guidance for common concerns as well as techniques for communicating with HCPs; these can help in the management of ASD and prevent complications (Grey et al., 2015). Common daily activities such as toileting, eating, and sleeping frequently present difficulties in family self-management of the child with ASD (Carbone, 2013; Giarelli, 2012). The evidence base for management of these activities is presented in the following sections.

\section{Toileting concerns}

Readiness for toileting may occur later than expected for children with ASD. Physiologic readiness differs from developmental readiness. For example, when the child has occasional dry diapers between changing, the child's urinary sphincter control is adequate to begin toilet training. Developmental readiness often occurs when children begin to notice they are wet, take off their own diaper, or even starting to smear stool (Autism Speaks, 2012a; Coucouvanis, 2008). The parent should prepare for toilet training by tracking the child's pattern and establishing regular toilet times and routines, including toileting when waking up, after meals, after drinks, before leaving home, when returning home, and at bedtime (Coucouvanis, 2008; Sanders, Mazzucchelli, \& Studman, 2009b). Table 1 outlines toileting strategies, which are also appropriate for typically developing children. Consistently following toileting "steps" with clear, simple instructions helps establish the routine for children with ASD; these steps can also be outlined on a visual schedule (Sanders et al., 2009a). Shaping behavior for sitting on the toilet for increasing lengths of time is necessary (Kroeger, 2012; Kroeger \& SorensenBurnworth, 2010). Environmental modifications including a toilet insert, sitting backward on the toilet, having a stepstool for the child's feet, and having activities to encourage sitting can increase the amount of time the child will sit on the toilet.

Readiness for toileting may occur later than expected for children with ASD.

\section{Table 1. Toilet training}

Child readiness

1. Dry 2 hours

2. Coordination to pull pants up and down

3. Able to follow simple directions

4. Aware he or she is wet
Parent preparations

1. Track child's patterns for 4 to 5 days

2. Check for wetness every 30 to 60 minutes

3. Develop consistent toileting "steps"

4. Increase fluids

5. Have rewards available

6. Provide activity for while on toilet
Establishing a toileting program

Goal: making it more fun to void in toilet than in pants

Boys should sit to void because this is more generalizable to sitting for bowel movements later 
7. Have underwear, toilet

insert, and step stool

for feet

Note. Data from Autism Speaks (2012a); Coucouvanis (2008); Kroeger (2012); Kroeger \& Sorensen-Burnworth (2010).

\section{Stool smearing}

Some children engage in stool smearing. Stool smearing may be an indicator that the child is aware and ready for toilet training, a response to a stressor the child is experiencing, an escape mechanism for a demand, or a sensory need. Using the "ABCs" of behavior and tracking the occurrence may be helpful in determining the reason behind the smearing. The recommendation is to remain calm and help the child clean himself or herself


also can help.

\section{Constipation}

$\underline{\text { Constipation and stool withholding have been reported to occur more frequently in children with ASD (Chandler }}$ et al., 2013; McElhanon, McCracken, Karpen, \& Sharp, 2014) and can interfere with attempts to toilet train. In well child and specialty care, all children with ASD should be assessed for problems related to gastrointestinal function, especially constipation. This problem is not always evident and is more difficult to determine in children who may be nonverbal, have sensory integrationdifficulties, or have feeding and diet restrictions. Children may experience large, hard bowel movements, inadequate evacuation, and/or stool impaction. The presence of these features can have an impact on day-to-day functioning, as demonstrated in behavior outbursts, disrupted sleep, and changes in eating patterns.

Because the problem of constipation in children with ASD is frequently encountered, treatment and management guidelines have been developed. The Autism Treatment Network Gastroenterology Committee has published a consensus statement with a constipation treatment algorithm (Furuta et al., 2012). Ten steps are outlined in this algorithm, and a constipation checklist is included to summarize these steps. "Red flags" necessitating workup and treatment include fewer than three bowel movements per week, difficult defecation, suspected impaction, and radiologic evidence of impaction. Parent/family education should include behavioral strategies and inclusion of fluids and fiber in the diet.

Oral treatments, such as polyethylene glycol mixed in a clear drink, are generally well tolerated and can be given on an as-needed basis or can be used as a "clean out" for stool withholding and/or impaction. Polyethylene glycol aids in keeping the stool content loose. Senna can be recommended to help stimulate the "urge" to have defecation. Ongoing follow-up appointments are important to assess the efficacy of the treatment plan and to provide ongoing support and education. Gastroenterology specialty referral is recommended if treatment has not been successful and chronic constipation has not resolved. Children with more severe features of autism may have continued difficulty related to their inability to sense fullness in the rectum or associate defecation with discomfort (Furuta et al., 2012).

\section{Mealtime problems}

Children with ASD experience mealtime problems, such as food selectivity (picky eating), more often than do typically developing children (Al-Khuffash, 2013; Kuschner, 2013; Schreck, Williams, \& Smith, 2004). Feeding 
difficultieshave been reported to be as high as $90 \%$ in children with ASD; these difficulties usually involve unwillingness to try new foods and compulsive rituals for eating (Kodak \& Piazza, 2008; Williams, Dalrymple, \& Neal, 2000). Picky eaters are at increased risk for nutritional deficits, being underweight, and subsequent poor cognitive development (Ekstein, Laniado, \& Glick, 2010; Oates, Peacock, \& Forrest, 1985). Thus, it is imperative to address picky eating behaviors to promote healthy growth and development.

Mealtime difficulties often include selective eating, ritualistic eating habits, or not sitting at the table to eat (Kuschner, 2013). The problem is multifactorial, and contributors can be sensory aversions, environment, feeding style, relationship issues, or personality (Dovey, Staples, Gibson, \& Halford, 2008; Smith, Roux, Naidoo, \& Venter, 2005; Wardle \& Cooke, 2008). Sensory aversions associated with feeding involve sensory profiles including touch, sight, taste, smell, and sound and heighten the eating challenges of children with ASD (Cermak, Curtin, \& Bandini, 2010; Nadon, Feldman, Dunn, \& Gisel, 2011).

HCPs should assess for and rule out health problems that might affect feeding. Gastrointestinal discomfort is common among children with ASD, and children may be selective about certain foods because they result in abdominal distress. Engaging the family to sort out additional health factors such as constipation, dental changes, or possible food allergies is crucial to the underlying health issues that can surround picky eating (Autism Speaks, 2014; Coury et al., 2012).

Gastrointestinal discomfort is common among children with ASD, and children may be selective about certain foods because they result in abdominal distress.

Children with ASD also may experience behavioral problems at mealtimes. Often these problems are related to the need for sameness and routine (Kuschner, 2013; Williams et al., 2000). Ritualistic eating behaviors such as foods not touching and mealtime problems including refusal of food that result in tantrums are frustrating for caregivers (Kuschner, 2013; Provost, Crowe, Osbourn, McClain, \& Skipper, 2010; Williams et al., 2000). Extreme limitations with eating may require a referral to an occupational therapist, feeding specialist, or dietician (Bass \& Kroeger, 2011).

A systematic review by Geraghty and colleagues found insufficient evidence to recommend a specific clinical protocol for the management of picky eating behaviors in children with ASD (Geraghty, Bates-Wall, RatliffSchaub, \& Lane, 2010). However, information for HCPs on establishing mealtime routines, the use of positive encouragement throughout the meal, and establishing simple mealtime rules can help (Mazzucchelli, Studman, \& Sanders, 2009). Table 2summarizes some strategies identified in the literature to assist HCPs with selected evidence-based approaches for establishing mealtime routines and feeding strategies for picky eaters.

Table 2. Mealtime strategies

Establish mealtime routines

Have child help with shopping for food

Have child help with mealtime preparation (e.g., setting the table and fixing food when appropriate)

Establish simple rules (e.g., wash hands, sit at table, food on plate, use utensils)
Picky eating strategies

Introduce one new food at a time, keeping the rest as accepted food

Establish the amount of new food to be introduced ( 1 teaspoon may be a good start)

Try new food more than a dozen trials before abandoning; offer different textures of the same food (e.g., chopping, blending) 
Establish mealtime routines

Eliminate external distractions (turn off TV and put cell phones away)

Keep the length of mealtime consistent (15 to 30 minutes)

Praise positive behavior (e.g., "good job touching the green bean") and ignore negative behavior such as throwing food

Use positive language such as "we hold our fork" instead of "don't throw your fork"

The caregiver should model eating or foodexploring behaviors

Use visual timers and visual schedules to communicate mealtime routines

Offer the same meal as the rest of the family
Picky eating strategies

The child may need to start with just having the food on the plate-then touching, smelling, and tasting food

Referral to an occupational therapist and dietician may be necessary

Offer accepted and nonaccepted food and alternate bites/licks/touches of each food using "first this, then this" instruction

Make eating fun with play such as dipping foods with sound effects, animal crackers jumping into a puddle of applesauce

Give the child choices chosen by the caregiver (two nonpreferred foods)

Decrease drinks provided during mealtime to avoid being too full

Offer food that is similar but different (e.g., if the child prefer apples, then try a similar fruit like a pear)

Note. Data from Autism Speaks (2014); Bass \& Kroeger (2011); Harpster, Burkett, Howell, Waldo, \& Fombo (2015); Kuschner (2013).

\section{Sleep concerns}

Sleep disturbances in children with ASD have been well described in the literature (Malow \& McGrew, 2008; Reynolds \& Malow, 2011; Richdale \& Schreck, 2009). When sleep is disordered or interrupted, all family members can experience distress. HCPs can provide valuable assistance and support to caregivers experiencing this problem. A practice pathway has been developed by The Sleep Committee of the Autism Treatment Network (Malow et al., 2012). The Committee recommends that all children with ASD be screened for insomnia and sleep problems. A questionnaire is recommended to determine if any underlying medical problems are present that affect sleep. After medical reasons have been ruled out, the first line of treatment is education/behavior interventions. Core behavioral deficits in children with ASD are taken into account when developing a behavioral approach. For example, following a nighttime routine can be very helpful in children who prefer sameness or routine in their daily schedule. An educational tool kit and pamphlet reviewing sleep strategies is available for families at the Autism Speaks Web site.

No medication has received Food and Drug Administration (FDA) approval for management of insomnia in children. Some benefit has been found in the use of melatonin to target delayed sleep onset (Andersen, Kaczmarska, McGrew, \& Malow, 2008). Melatonin is usually well tolerated and has not been found to have serious adverse effects. Ongoing medical follow up is recommended by the Sleep Committee of the Autism Treatment Network to assess response to behavioral and medical intervention (Malow et al., 2012). 


\section{Managing Challenging Behavior in the Primary Care Setting}

Although challenging behaviors occur in the home, they also occur in stressful situations such as the health care setting. In the primary care setting, recognizing and understanding antecedents, or triggers, to behaviors the child may be exhibiting is crucial in preventing challenging behaviors that can complicate delivery of care. The following questions can help the HCP identify triggers for behavior: Is the child trying to communicate pain or physical discomfort related to a medical concern? Is the child trying to avoid the situation to escape the event or situation? Is the child seeking attention? Is the child trying to make a communication request but does not have the words to describe what he or she wants? Is the child affected by sensory overload related to lights, noises, or a crowded situation? Antecedents prompt and cue a behavior; therefore, eliminating the trigger can prevent the challenging behavior (Noonan \& McCormick, 2006).

In the primary care setting, recognizing and understanding antecedents, or triggers, to behaviors the child may be exhibiting is crucial in preventing challenging behaviors that can complicate delivery of care.

\section{Preparing the Environment}

Environmental modifications have been found to be helpful in reducing challenging behaviors in the health care environment (Davignon, Friedlaender, Cronholm, Paciotti, \& Levy, 2014; Kopecky, Broder-Fingert, lannuzzi, \& Connors, 2013). Waiting areas may be overwhelming in size, leaving ample opportunity for children to wander, or they may be overcrowded and loud. Some children may benefit from a larger, more open waiting area, whereas other children may be more comfortable in a smaller, quieter examination room (Bultas, 2012). Therefore, identifying where the child "waits" best can be beneficial. Reducing bright lighting and loud noises/alarms in waiting areas and patient care areas is also helpful because children with ASD are often hypersensitive to this stimulation (Scarpinato et al., 2010). Reducing wait times can decrease anxiety and boredom behaviors. Other supports include the availability of a variety of manipulative toys to play with, fish tanks to look at, books to read, or iPad applications that provide the child with something entertaining to do while they wait (Bultas, 2012).

\section{Preparing the Child}

Preparing the child for the health care encounter is also helpful in reducing challenging behaviors and anxiety in the health care setting (Drake, Johnson, Stoneck, Martinez, \& Massey, 2011). Child-friendly books that provide information about the visit or procedure can be purchased or made and should be available in both waiting and patient care areas. When making books, using actual photographs of the office, health care environment, and personnel the child may be encountering provides additional context for the child.

Visual/picture schedules can be used to help prepare children with ASD and reduce their anxiety in novel situations (Chebuhar, McCarthy, Bosch, \& Baker, 2013). A visual schedule uses photographs or simple pictures to outline the steps or events that will be occurring during the health care encounter; they help the child understand and know what to expect (Chebuhar et al., 2013; McClannahan \& Krantz, 2010). Social Stories are another tool for preparing a child for an unfamiliar or nonroutine situation (Kokina \& Kern, 2010). Social Stories outline expected behaviors and responses to help children understand how they should act and react (Grav, 2010). The text and pictures are individualized for the situation. Social Stories for common situations can be purchased, or a Social Story can be specifically written to fit a situation. 


\section{Shared Decision Making}

Shared decision making between HCPs and parents optimizes health care outcomes (Koller \& Goldman, 2012; Kopecky et al., 2013; Strauss et al., 2015), and therefore it is essential to work with the parent or caregiver who is present with the child. Parents of children with ASD have a keen sense of understanding of their child (Bultas, 2012; Johnson, Bekhet, Robinson, \& Rodriguez, 2014; Scarpinato et al., 2010). Proactive planning with parents can identify specific antecedents to behavior, early signs that indicate the child is becoming upset, and best communication methods, and it can identify modifications that enhance the delivery and flow of the health care services (Balakas, Gallaher, \& Tillev, 2015; Davignon et al., 2014).

\section{Cultural Implications for Management}

Several studies describe family care among African American and Latino families who have children with ASD (Burkett, Morris, Manning, Anthony, \& Shambley-Ebron, 2015; Carr \& Lord, 2013; Magana, Parish, Rose, Timberlake, \& Swaine, 2012; Magana \& Smith, 2006; Zuckerman et al., 2014). Broad themes of protective care, strong family support, and others' support, along with taking action for their child and family, were identified for both cultural groups. Challenges described from the families' perspective are largely focused on distrust, poorer quality of care, health care access, knowledge deficit in ASD, and stigma. The challenges culturally diverse families encounter can delay seeking or receiving health care for their child with ASD (Burkett et al., 2015; Kerfeld, Hoffman, Ciol, \& Kartin, 2011).

\section{Supports During Examination and Procedures}

One should start by identifying and prioritizing the parts and pieces of the examination that are essential and leave uncomfortable parts of the examination for last. For uncomfortable or anxiety-provoking parts of the examination, distraction or relaxation techniques can be used. Distraction techniques include blowing bubbles, singing, or providing handheld spinning toys or squishy balls for the child to manipulate or hold; relaxation might include deep breathing exercises (Drake et al., 2011). When children engage in ritualistic or obsessive behaviors, such as humming or flicking fingers, HCPs should recognize that these behaviors are coping mechanisms used to reduce anxiety or fear, and the behaviors should not be stopped (Johnson, Lashley, Stonek, \& Bonjour, 2012). Slowing down the process, allowing additional time for transitions between procedures or parts of the examination, and providing rewards/reinforcements to positively shape behavior also improve the child's compliance with the examination or procedure.

\section{Communication with the Child}

Children with ASD have difficulty with communication, social cues, facial expressions, sarcasm, and jokes (Imaizumi, Furuya, \& Yamasaki, 2009); therefore, communication should be straightforward. Improving communication with the child reduces fears, anxiety, and the need to use physical force during the examination or health care procedure. First, visual instruction may be processed more easily than verbal instruction (Bellando

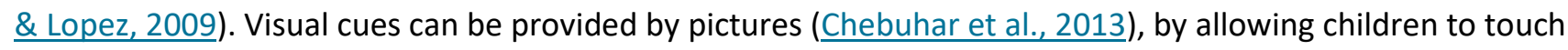
and see equipment, or by using a visual/picture schedule of the planned events.

When providing verbal instruction, reducing the number of commands, speaking slowly to allow for additional time for processing of information, and repeating instructions may be necessary (Tucker, Derscheid, Odegarden, \& Olson, 2008). Multiple commands or several step directions are often difficult for children with ASD to process quickly, especially in unfamiliar environments. Instructions should be clear and free of sarcasm and jokes. Additionally, multiple voices in a room can be confusing and difficult for the child to distinguish between when 
following instructions. It is recommended that one person or "one voice" at a time be used (Johnson et al., 2012).

Another suggestion for communicating instructions includes the use of directives such as "First, Then" phrases (Loring \& Hamilton, 2011). These phrases provide the child with concrete information related to what is happening and what is expected of him or her; these phrases help the child complete a task or a request. A reward or desired outcome may be used in the "then" phrase. Also, HCPs should not forget the influence that positive reinforcement and verbal praise has on shaping appropriate or desired behavior.

The availability of a communication board or communication cards during the examination or procedure provides children with a way to express themselves and a sense of control (Scarpinato et al., 2010). The inability to communicate frequently leads to frustration and externalizing of challenging behaviors. When developing or choosing communication boards or cards for the health care setting, pictures or symbols that would help the child communicate pain or discomfort, initiate requests, and verbalize feelings should be included, along with pictures of common instruments or procedures used. Communication symbols and cards, including those specific to health care, are widely available via the Internet.

\section{Medication and Immunizations}

Giving oral medications may not be easy because of a child's oral and/or textural aversions. Because the decision to begin medication management can be difficult for caregivers, it should be a joint collaboration between the caregiver and the HCP. A full and frank discussion of possible benefits and adverse effects is necessary for parents to be fully informed of the risk and benefits of the treatment. Parents often use complementary and alternative medications, most of which have not been studied for efficacy in children with ASD (Levy \& Hyman, 2008; Lofthouse, Hendren, Hurt, Arnold, \& Butter, 2012; Perrin et al., 2012). Keeping immunizations up to date is encouraged. No evidence exists that links vaccinations to autism (Miller \& Reynolds, 2009; Smeeth et al., 2004).

\section{Managing Challenging Behaviors in the Acute Care Setting}

The acute health care environment is often loud, fast-paced, brightly lit, and fraught with long wait times for patients. Children with ASD frequently experience sensory overload in situations with these characteristics, such as an emergency department, which may trigger behavioral reactions beyond their norm (Johnson et al., 2014; Scarpinato et al., 2010). Additionally, communication difficulties and novel environments can be confusing and even frightening for a child who may not fully understand social cues and health care routines. Challenging behaviors exhibited by children with ASD in the health care setting, often a result of boredom, anxiety or fear, may include screaming, crying, tantrums, aggression, apathy, and lack of cooperation with providers (Bultas, 2012).

HCPs may not have the skills necessary to address difficult and challenging behaviors externalized by children with developmental disabilities such as ASD (Scarpinato et al., 2010). Externalized child behaviors not only lead to difficult or delayed treatment but also can be a safety concern when the HCP is not comfortable or confident in addressing them (Johnson et al., 2012). The ability of the HCP to remain calm and recognize early signs of fear, anxiety, or stress in the child is crucial in reducing externalized challenging behaviors (Johnson et al., 2012).

Various factors influence a child's ability to tolerate or cooperate during potentially anxiety-provoking procedures or appointments in the health care setting. Previous similar experiences, such as a dental visit that may have been emotionally traumatic, may result in the failure to attend future appointments. Children with 
ASD may have tantrums during acute episodic health care if the exact words and order of events are not followed at subsequent visits, as a result of their rigid need for sameness in daily routines (Johnson et al., 2014). The use of visual (picture) schedules for foreshadowing is also recommended to allow the child to understand the expected routine (Chebuhar et al., 2013).

Many settings can be overwhelming sensory experiences for the child with ASD (Johnson et al., 2014). Emergency department noise was found to be the highest in the waiting room (Giarelli, 2012), pointing to a recommendation to prioritize moving children with ASD to an examination room. Child life specialists have been very helpful in collaborating with families using shared decision making to prepare children with ASD for these appointments, because parents know the behavioral triggers for their children (Strauss et al., 2015).

When a procedure or acute care setting appointment is planned that may be difficult, a psychosocial risk assessment can be obtained. An assessment tool that has been developed for this purpose, The Psychosocial Risk Assessment in Pediatrics, is used to elicit valuable information from the parents to help plan for a successful visit (Staab, Klayman, \& Lin, 2014). The child life clinician reviews this information and collaborates with the medical provider to determine whether the child would benefit from additional preparation and support. Children with developmental and behavioral challenges who have difficulty tolerating ambulatory health care encounters even with nonpharmacological support interventions may be prescribed pre-procedural oral anxiolytic medication. Contraindications based on history and physical examination include (a) major craniofacial airway abnormalities, (b) obstructive sleep apnea, and (c) major cardiac anomalies (Staab et al., 2014). Recommended oral anxiolytic medications are as follows: first line, clonazepam; second line, risperidone; and third line, for adolescents and young adults, lorazepam (Dixon, Klayman, \& Reinhold, 2011).

Research is limited on the effect of interventions to decrease anxiety of children with ASD who are undergoing medical procedures. Johnson and colleagues (2014) studied the effect of a social script-based iPad application to prepare children with ASD $(n=32)$ and their parent for medical imaging. Findings from this pilot study showed lower state anxiety for parents and children compared with the parents whose children were not exposed to the application and fewer externalized challenging child behaviors than in the control group (Johnson et al., 2014). Autism Speaks developed several tool kits for procedure preparation (available at the Web site www.autismspeaks.org) that can be used during acute episodic health care to prevent challenging child behaviors.

\section{Staff Training}

Preparation of hospital staff has also yielded more favorable outcomes for children with ASD. In one study, the meaning attributed to children's challenging behaviors by the mothers and the NPs differed; mothers attributed behaviors to the child's frustration, hyperactivity, and self-calming, whereas NPs attributed challenging behaviors to self-stimulation and child aggression (Johnson et al., 2014). The difference in attribution of causality could lead to different reactions to the behaviors. In another study evaluating a training program at a pediatric hospital, nursing staff reported increased knowledge and decreased fear when caring for children with developmental disabilities and challenging behaviors (Johnson et al., 2012). The training, required as part of new employee orientation, focused on preventing and managing challenging child behaviors. Strategies included consulting parents to learn the individual behavior triggers and communication patterns of their child, including how he or she expresses pain; having only one person talking at a time; modifying the environment; and structuring communication, but letting the child know what one is about to do (Johnson et al., 2012). Training alerts the staff to the availability of a "Coping Kit" that can be provided to support children with ASD in the acute 
care setting. The Coping Kit includes items such as communication cards, appropriate toys, and other items to help the child self-calm. In a study of 24 nurses who used the Coping Kit, the majority $(n=17,70.8 \%)$ perceived that it helped their patients be less anxious during procedures (Drake et al., 2011).

For children going to surgery, Scully (2015) reports on a similar program of staff training and a perioperative tool kit. The tool kit contains a checklist for the child's characteristic behaviors and a social script explaining each step of the perioperative procedure, illustrated with accurate pictures to be used at home for preparation regarding what to expect on the day of the surgery. Other items included in the tool kit to decrease challenging behaviors of the child with ASD are sensory materials; information on guardianship, informed consent, and or surrogate decision making; and an informational brochure ( $\underline{\text { Scully, 2015). }}$.

\section{Conclusion}

Providing health care services to the growing population of children with ASD can be challenging because of the range of symptoms and behaviors exhibited. HCPs can reduce challenging behaviors in the home and in the health care setting with advanced preparation such as environmental adaptations, collaborating with parents during the health care encounter, using appropriate communication strategies, and understanding antecedents to challenging behaviors. Additionally, HCP knowledge of evidence-based recommendations for family selfmanagement of daily living skills and behaviors increase the likelihood of better health care outcomes for children with ASD. HCPs can access many educational and behavioral supports using a variety of evidence-based online supports available to both parents and providers.

\section{References}

Al-Khuffash, $2013 \mathrm{~S}$. Al-Khuffash. A comparison of eating problems among children with autism, mental retardation and children with normal development. Higher Education of Social Science, 4 (3) (2013), pp. 40-45

Andersen et al., 2008 I.M. Andersen, J. Kaczmarska, S.G. McGrew, B.A. Malow. Melatonin for insomnia in children with autism spectrum disorders. Journal of Child Neurology, 23 (5) (2008), pp. 482-485

Autism Speaks, 2012a. Autism Speaks. ATN/AIR-P parent's guide to toilet training in autism. (2012). Retrieved from https://www.autismspeaks.org/science/resources-programs/autism-treatment-network/atn-air-ptoilet-training

Autism Speaks, 2012b. Autism Speaks. Challenging behaviors tool kit. (2012). Retrieved from https://www.autismspeaks.org/family-services/tool-kits/challenging-behaviors-tool-kit

Autism Speaks, 2014. Autism Speaks. ATN/AIR-P guide to exploring feeding behavior in autism. (2014). Retrieved from https://www.autismspeaks.org/science/find-resources-programs/autism-treatmentnetwork/tools-you-can-use/atn-air-p-guide-exploring-feeding-behavior

Balakas et al., 2015. K. Balakas, C.S. Gallaher, C. Tilley. Optimizing perioperative care for children and adolescents with challenging behaviors. MCN. The American Journal of Maternal Child Nursing, 40 (3) (2015), pp. 153-159

Bass and Kroeger, 2011. J. Bass, K. Kroeger. Feeding. J.K. Luiselli (Ed.), Teaching and behavior support for children and adults with autism spectrum disorders: A "how to" practitioner's guide, Oxford University Press, New York, NY (2011)

Bavolek, 1989. S.J. Bavolek. Assessing and treating high-risk parenting attitudes. Early Child Development and Care, 42 (1) (1989), pp. 99-112

Bellando and Lopez, 2009. J. Bellando, M. Lopez. The school nurse's role in treatment of the student with autism spectrum disorders. Journal for Specialists in Pediatric Nursing, 14 (3) (2009), pp. 173-182 
Bultas, 2012. M.W. Bultas. The health care experiences of the preschool child with autism. Journal of Pediatric Nursing, 27 (5) (2012), pp. 460-470

Burkett et al., 2015. K. Burkett, E. Morris, P. Manning, J. Anthony, D. Shambley-Ebron. African American families on autism diagnosis and treatment: The influence of culture. Journal of Autism and Developmental Disorders, 45 (10) (2015), pp. 3244-3254

Carbone, 2013. P.S. Carbone. Moving from research to practice in the primary care of children with autism spectrum disorders. Academic Pediatrics, 13 (5) (2013), pp. 390-399

Carr and Lord, 2013. T. Carr, C. Lord. Longitudinal study of perceived negative impact in African American and Caucasian mothers of children with autism spectrum disorder. Autism, 17 (4) (2013), pp. 405-417

Cermak et al., 2010. S.A. Cermak, C. Curtin, L.G. Bandini. Food selectivity and sensory sensitivity in children with autism spectrum disorders. Journal of the American Dietetic Association, 110 (2) (2010), pp. 238246

Chandler et al., 2013. S. Chandler, I. Carcani-Rathwell, T. Charman, A. Pickles, T. Loucas, D.Meldrum, et al., G. Baird. Parent-reported gastro-intestinal symptoms in children with autism spectrum disorders. Journal of Autism and Developmental Disorders, 43 (12) (2013), pp. 2737-2747

Chebuhar et al., 2013. A. Chebuhar, A.M. McCarthy, J. Bosch, S. Baker. Using picture schedules in medical settings for patients with an autism spectrum disorder. Journal of Pediatric Nursing, 28 (2) (2013), pp. 125-134

Coucouvanis, 2008. J. Coucouvanis. The potty journey: Guide to toilet training children with special seeds, including autism and related disorders. Autism Asperger Publishing Company, Shawnee Mission, KS (2008)

Coury et al., 2012. D.L. Coury, P. Ashwood, A. Fasano, G. Fuchs, M. Geraghty, A. Kaul, et al., N.E. Jones. Gastrointestinal conditions in children with autism spectrum disorder: Developing a research agenda. Pediatrics, 130 (suppl. 2) (2012), pp. S160-S168

Davignon et al., 2014. M.N. Davignon, E. Friedlaender, P.F. Cronholm, B. Paciotti, S.E. Levy. Parent and provider perspectives on procedural care for children with autism spectrum disorders. Journal of Developmental \& Behavioral Pediatrics, 35 (3) (2014), pp. 207-215

Dixon et al., 2011. B. Dixon, G.J. Klayman, J.A. Reinhold. Best Evidence Statement (BESt): Oral anxiolytic medication prior to ambulatory healthcare encounters for individuals with special developmental and behavioral challenges. (2011). Retrieved from www.cincinnatichildrens.org/workarea/linkit.aspx?linkidentifier=id\&;itemid=87979\&libid=87667

Dovey et al., 2008. T.M. Dovey, P.A. Staples, E.L. Gibson, J.C. Halford. Food neophobia and 'picky/fussy' eating in children: A review. Appetite, 50 (2) (2008), pp. 181-193

Drake et al., 2011. J. Drake, N. Johnson, A.V. Stoneck, D.M. Martinez, M. Massey. Evaluation of a coping kit for children with challenging behaviors in a pediatric hospital. Pediatric Nursing, 38 (4) (2011), pp. 215-221

Ekstein et al., 2010. S. Ekstein, D. Laniado, B. Glick. Does picky eating affect weight-for-length measurements in young children? Clinical Pediatrics, 49 (3) (2010), pp. 217-220

Furuta et al., 2012. G.T. Furuta, K. Williams, K. Kooros, A. Kaul, R. Panzer, D.L. Coury, et al., G. Fuchs. Management of constipation in children and adolescents with autism spectrum disorders. Pediatrics, 130 (suppl. 2) (2012), pp. S98-S105

Geraghty et al., 2010. M.E. Geraghty, J. Bates-Wall, K. Ratliff-Schaub, A.E. Lane. Nutritional interventions and therapies in autism: A spectrum of what we know: Part 2. ICAN: Infant, Child, \& Adolescent Nutrition, 2 (2) (2010), pp. 120-133

Giarelli, 2012. E. Giarelli. Introduction to the integrated, comprehensive nursing care of autism spectrum disorder. E. Giarelli, M.R. Gardner (Eds.), Nursing of autism spectrum disorder: Evidence-based integrated care across the lifespan, Springer, New York, NY (2012), pp. 45-72

Goodson and Bronson, n.d. Goodson, B., \& Bronson, M. (n.d.). Which toy for which child: A consumers guide for selecting suitable toys. Retrieved from http://www.cpsc.gov/PageFiles/122511/285.pdf 
Gray, 2010. C. Gray. The new social story book. Future Horizons, Arlington, TX (2010)

Grey et al., 2015. M. Grey, D. Schulman-Green, K. Knafl, N.R. Reynolds. A revised self- and family management framework. Nursing Outlook, 63 (2) (2015), pp. 162-170

Gurney et al., 2006. J.G. Gurney, M.L. McPheeters, M.M. Davis. Parental report of health conditions and health care use among children with and without autism: National Survey of Children's Health. Archives of Pediatrics \& Adolescent Medicine, 160 (8) (2006), pp. 825-830

Harpster et al., 2015. K. Harpster, K. Burkett, D. Howell, C. Waldo, D. Fombo. Snack time training program for children with autism spectrum disorder and their caregivers. Meeting abstract from Regional Symposium of Leadership Education in Neurodevelopmental and Related Disabilities (LEND), Cincinnati, $\mathrm{OH}(2015)$

Imaizumi et al., 2009. S. Imaizumi, I. Furuya, K. Yamasaki. Voice as a tool communicating intentions. Logopedics Phoniatrics Vocology, 34 (4) (2009), pp. 196-199

Johnson et al., 2012. N. Johnson, J. Lashley, A. Stonek, A. Bonjour. Children with developmental disabilities at a pediatric hospital: Staff education to prevent and manage challenging behaviors. Journal of Pediatric Nursing, 27 (6) (2012), pp. 742-749

Johnson et al., 2014. N. Johnson, A. Bekhet, K. Robinson, D. Rodriguez. Attributed meanings and strategies to prevent challenging behaviors of hospitalized children with autism: Two perspectives. Journal of Pediatric Health Care, 28 (5) (2014), pp. 386-393

Kerfeld et al., 2011. C.I. Kerfeld, J.M. Hoffman, M.A. Ciol, D. Kartin. Delayed or forgone care and dissatisfaction with care for children with special health care needs: The role of perceived cultural competency of health care providers. Maternal Child Health Journal, 15 (4) (2011), pp. 487-496

Kodak and Piazza, 2008. T. Kodak, C.C. Piazza. Assessment and behavioral treatment of feeding and sleeping disorders in children with autism spectrum disorders. Child and Adolescent Psychiatric Clinics of North America, 17 (4) (2008), pp. 887-905

Kokina and Kern, 2010. A. Kokina, L. Kern. Social Story ${ }^{\mathrm{TM}}$ interventions for students with autism spectrum disorders: A meta-analysis. Journal of Autism and Developmental Disorders, 40 (7) (2010), pp. 812-826

Koller and Goldman, 2012. D. Koller, R. Goldman. Distraction techniques for children undergoing procedures: A critical review of pediatric research. Journal of Pediatric Nursing, 27 (6) (2012), pp. 652-681

Kopecky et al., 2013. K. Kopecky, S. Broder-Fingert, D. Iannuzzi, S. Connors. The needs of hospitalized patients with autism spectrum disorders: A parent survey. Clinical Pediatrics, 52 (7) (2013), pp. 652-660

Kroeger, 2012. K.A. Kroeger. Toilet training. F.R. Volkmar (Ed.), Encyclopedia of autism spectrum disorders, Springer, New York, NY (2012)

Kroeger and Sorensen-Burnworth, 2010. K.A. Kroeger, R. Sorensen-Burnworth. A parent training model for toilet training children with autism. Journal of Intellectual Disability Research, 54 (2010), pp. 556-567

Kuschner, 2013. E. Kuschner. Seven ways to help a picky eater with autism. (2013). Retrieved from https://www.autismspeaks.org/family-services/health-and-wellness/nutrition/seven-ways-help-pickyeater-autism

Levy and Hyman, 2008. S.E. Levy, S. Hyman. Complementary and alternative medicine treatments for children with autism spectrum disorders. Child Adolescent Psychiatry Clinics of North America, 17 (4) (2008), pp. 803-820

Liptak et al., 2006. G.S. Liptak, T. Stuart, P. Auinger. Health care utilization and expenditures for children with autism: Data from U.S. national samples. Journal of Autism and Developmental Disorders, 36 (7) (2006), pp. 871-879

Lofthouse et al., 2012. N. Lofthouse, R. Hendren, E. Hurt, L.E. Arnold, E. Butter. A review of complementary and alternative treatments for autism spectrum disorders. Autism Research and Treatment, 2012 (2012), p. 870391

Loring and Hamilton, 2011. W. Loring, M. Hamilton. Visual supports and autism spectrum disorders. (2011). Retrieved from http://www.autismspeaks.org/docs/sciencedocs/atn/visual supports.pdf 
Magana et al., 2012. S. Magana, S. Parish, R. Rose, M. Timberlake, J. Swaine. Racial and ethnic disparities in quality of health care among children with autism and other developmental disabilities. Intellectual and Developmental Disabilities, 50 (4) (2012), pp. 287-299

Magana and Smith, 2006. S. Magana, M. Smith. Psychological distress and well-being of Latina and non-Latina white mothers of youth and adults with an autism spectrum disorder: Cultural attitudes towards coresidence status. American Journal of Orthopsychiatry, 76 (3) (2006), pp. 346-357

Malow et al., 2012. B.A. Malow, K. Byars, K. Johnson, S. Weiss, P. Bernal, S.E. Goldman, et al., D.G. Glaze. A practice pathway for the identification, evaluation, and management of insomnia in children and adolescents with autism spectrum disorders. Pediatrics, 130 (suppl. 2) (2012), pp. S106-S124

Malow and McGrew, 2008. B.A. Malow, S.G. McGrew. Sleep disturbances and autism. Sleep Medicine Clinics, 3 (3) (2008), pp. 479-488

Mandell et al., 2006. D.S. Mandell, J. Cao, R. Ittenbach, J. Pinto-Martin. Medicaid expenditures for children with autistic spectrum disorders: 1994 to 1999. Journal of Autism and Developmental

Disorders, 36 (4) (2006), pp. 475-485

Mayes et al., 2012. S.D. Mayes, S.L. Calhoun, R. Aggarwal, C. Baker, S. Mathapati, R.Anderson, et al., C. Petersen. Explosive, oppositional, and aggressive behavior in children with autism compared to other clinical disorders and typical children. Research in Autism Spectrum Disorders, 6 (1) (2012), pp. 1-10

Mazzucchelli et al., 2009. T. Mazzucchelli, L. Studman, M. Sanders. Stepping Stones Triple P: A guide to mealtimes. The University of Queensland and Disability Services Commission of Western Australia, Queensland, Australia (2009)

McClannahan and Krantz, 2010. L.E. McClannahan, P.J. Krantz. Activity schedules for children with autism: Teaching independent behavior. (2nd ed.), Woodbine House, Bethesda, MD (2010)

McElhanon et al., 2014. B.O. McElhanon, C. McCracken, S. Karpen, W.G. Sharp. Gastrointestinal symptoms in autism spectrum disorder: A meta-analysis. Pediatrics, 133 (5) (2014), pp. 872-883

McMillin et al., 2015. S.E. McMillin, M.W. Bultas, J. Wilmott, S. Grafeman, D.H. Zand. Rapid-response parenting intervention in diagnostic centers as a patient-centered innovation for autism spectrum disorders. Journal of Autism and Developmental Disorders, 45 (1) (2015), pp. 269-271

Miller and Reynolds, 2009. L. Miller, J. Reynolds. Autism and vaccination-The current evidence. Journal for Specialists in Pediatric Nursing, 14 (3) (2009), pp. 166-172

Minnes and Steiner, 2009. P. Minnes, K. Steiner. Parent views on enhancing the quality of health care for their children with fragile $\mathbf{X}$ syndrome, autism or Down syndrome. Child: Care, Health and Development, 35 (2) (2009), pp. 250-256

Nadon et al., 2011. G. Nadon, D.E. Feldman, W. Dunn, E. Gisel. Association of sensory processing and eating problems in children with autism spectrum disorders. Autism Research \& Treatment, 2011 (2011), p. 541926

Noonan and McCormick, 2006. M.J. Noonan, L. McCormick. Young children with disabilities in natural environments: Methods and procedures. Paul H. Brookes Publishing Company, Baltimore, MD (2006)

Oates et al., 1985. R.K. Oates, A. Peacock, D. Forrest. Long-term effects of nonorganic failure to thrive. Pediatrics, 75 (1) (1985), pp. 36-40

Perrin et al., 2012. J.M. Perrin, D.L. Coury, S.L. Hyman, L. Cole, A.M. Reynolds, T. Clemons. Complementary and alternative medicine use in a large pediatric autism sample. Pediatrics, 130 (suppl. 2) (2012), pp. S77S82

Provost et al., 2010. B. Provost, T. Crowe, P. Osbourn, C. McClain, B. Skipper. Mealtime behaviors of preschool children: Comparison of children with autism spectrum disorder and children with typical development. Physical \& Occupational Therapy in Pediatrics, 30 (3) (2010), pp. 220-233

Reynolds and Malow, 2011. A.M. Reynolds, B.A. Malow. Sleep and autism spectrum disorders. Pediatric Clinics of North America, 58 (3) (2011), pp. 685-698 
Rhoades et al., 2007. R.A. Rhoades, A. Scarpa, B. Salley. The importance of physician knowledge of autism spectrum disorder: Results of a parent survey. BMC Pediatrics, 7 (2007), p. 37

Richdale and Schreck, 2009. A.L. Richdale, K.A. Schreck. Sleep problems in autism spectrum disorders:

Prevalence, nature, \& possible biopsychosocial aetiologies. Sleep Medicine Reviews, 13 (6) (2009), pp. 403-411

Sanders et al., 2009a. M. Sanders, T. Mazzucchelli, L. Studman. Stepping Stones Triple P: A guide to positive parenting. The University of Queensland and Disability Services Commission of Western

Australia, Queensland, Australia (2009)

Sanders et al., 2009b. M. Sanders, T. Mazzucchelli, L. Studman. Stepping Stones Triple P: A guide to toileting. The University of Queensland and Disability Services Commission of Western Australia, Queensland, Australia (2009)

Scarpinato et al., 2010. N. Scarpinato, J. Bradley, K. Kurbjun, X. Bateman, B. Holtzer, B. Ely. Caring for the child with an autism spectrum disorder in the acute care setting. Journal for Specialists in Pediatric Nursing, 15 (3) (2010), pp. 244-254

Schreck et al., 2004. K.A. Schreck, K. Williams, A.F. Smith. A comparison of eating behaviors between children with and without autism. Journal of Autism and Developmental Disorders, 34 (4) (2004), pp. 433-438

Scully, 2015. S.M. Scully. Opening up the perioperative autism toolkit. OR Nurse, 9 (3) (2015), pp. 40-47

Smeeth et al., 2004. L. Smeeth, C. Cook, E. Frombonne, L. Heavey, L. Rodrigues, P. Smith, et al., A. Hall. MMR vaccination and pervasive developmental disorders: A case-control study. Lancet, 364 (9438) (2004), pp. 963-969

Smith et al., 2005. A.M. Smith, S. Roux, N.R. Naidoo, D.J. Venter. Food choices of tactile defensive children. Nutrition, 21 (1) (2005), pp. 14-19

Staab et al., 2014. J.H. Staab, G.J. Klayman, L. Lin. Assessing pediatric patient's risk of distress during healthcare encounters: The psychometric properties of the Psychosocial Risk Assessment in Pediatrics. Journal of Child Health Care, 18 (4) (2014), pp. 378-387

Strauss et al., 2015. K. Strauss, A. Benvenuto, B. Battan, M. Siracusano, M. Terribili, P.Curatolo, et al., L. Fava. Promoting shared decision making to strengthen outcome of young children with autism spectrum disorders: The role of staff competence. Research in Developmental Disabilities, 38 (2015), pp. 48-63

Tregnago and Cheak-Zamora, 2012. M.K. Tregnago, N.C. Cheak-Zamora. Systematic review of disparities in health care for individuals with autism spectrum disorders in the United States. Research in Autism Spectrum Disorders, 6 (3) (2012), pp. 1023-1031

Tucker et al., 2008. S. Tucker, D. Derscheid, S. Odegarden, M.E. Olson. Evidence-based training for enhancing psychiatric nurses' child behavior management skills. Journal for Nurses in Professional Development, 24 (2) (2008), pp. 75-85

Wardle and Cooke, 2008. J. Wardle, L. Cooke. Genetic and environmental determinants of children's food preferences. British Journal of Nutrition, 99 (S1) (2008), pp. S15-S21

Webster-Stratton and Mihalic, 2001. C. Webster-Stratton, S.F. Mihalic. The incredible years: Parent, teacher and child training series. Center for the Study and Prevention of Violence, Institute of Behavioral Science, University of Colorado at Boulder, Boulder, CO (2001)

Weil and Inglehart, 2010. T.N. Weil, M.R. Inglehart. Dental education and dentists' attitudes and behavior concerning patients with autism. Journal of Dental Education, 74 (12) (2010), pp. 1294-1307

Williams et al., 2000. P.G. Williams, N. Dalrymple, J. Neal. Eating habits of children with autism. Pediatric nursing, 26 (3) (2000), p. 259

Wu et al., 2015. C.-M. Wu, P.-T. Kung, C.-I. Li, W.-C. Tsai. The difference in medical utilization and associated factors between children and adolescents with and without autism spectrum disorders. Research in Developmental Disabilities, 36 (2015), pp. 78-86 
Zuckerman et al., 2014. K. Zuckerman, B. Sinche, M. Cobian, M. Cervantes, A. Mejia, T.Becker, et al., C. Nicolaidis. Conceptualization of autism in the Latino community and its relationship with early diagnosis. Journal of Developmental and Behavioral Pediatrics, 35 (8) (2014), pp. 522-532 